SHORT COMMUNICATION

\title{
Novel Shape Memory Using Delay and Thermal Hysteresis of Crystalline Phase Transition in Cross-Linked Polybutylene Succinate
}

\author{
By Kazuhiko INOUE* and Midori YAMASHIRO
}

KEY WORDS: Shape Memory / Biodegradable / Polybutylene Succinate / Heat Resistant / Hysteresis / Crystalline Phase Transition /

Intelligent polymers, materials whose shape or color changes according to environmental conditions (acidity, light, temperature, electric field, etc.), have potential applications in many fields. A durable shape memory polymer, for example, would be useful in medicine, automotive applications, and aerospace engineering. A shape memory polymer generally consists of a thermoplastic phase and a frozen phase. ${ }^{1-3}$ The initial shape is memorized in the frozen phase and can be recovered through the shape memory effect. The creation of the frozen phase therefore strongly affects the performance of shape memory. The frozen phase of a durable shape memory polymer must be rigidly formed using a cross-linked structure with stable covalent bonds like those in a cross-linked trans-polyisoprene. ${ }^{1,2,45}$ The thermoplastic phase affects the ease of deformation and the heat resistance of the deformed shape. When the phase transition of the thermoplastic phase is a glass transition, deformation and fixation are normally carried out around the same temperature. When the phase transition of the thermoplastic phase is a crystalline transition, though, the transition temperatures for deformation and fixation differ somewhat. ${ }^{6-8}$ There is, however, no conventional shape memory polymer that can be easily deformed at temperatures around room temperature and whose deformed is highly heat-resistant.

In this study we used polyisocyanate linkers to make cross-linked polybutylene succinates (PBSs) that have an attractive shape memory performance: easy deformation at room temperature and high heatresistance of deformed shape. This performance is due to expansion of the thermal hysteresis of the crystalline phase-transition temperature and to delay of the crystallization time.

\section{EXPERIMENTAL}

Five compounds (Table I) were synthesized by using polyisocyanate linkers-either lysine tri-isocyanate (LTI), 1, 3, 5-tris(6-isocyanatohexyl) isocyanate (TIHI), or hexamethylene diisocyanate (HMD)to cross-link PBS macromonomers of various sizes (Scheme 1). The macromonomers were obtained by ester exchange reaction between $250 \mathrm{~g}$ of PBS $\left(M_{\mathrm{n}}=40,000\right)$ and 1,4-butanediol at $200^{\circ} \mathrm{C}$ for $4.5 \mathrm{~h}$ and subsequent purification by reprecipitation with chloroform and methanol (45 g 1,4-butanediol for $M_{\mathrm{n}(\mathrm{NMR})}=1200,23 \mathrm{~g}$ 1,4-butanediol for $M_{\mathrm{n}(\mathrm{NMR})}=1900$, and $12 \mathrm{~g}$ 1,4-butanediol for $\left.M_{\mathrm{n}(\mathrm{NMR})}=2900\right)$. Compounds 1, 2, 3, and 4 were three-dimensional networks because their cross-linkers had three functional groups, and compound $\mathbf{5}$ was a linear polymer because its cross-linker had only two functional groups. The deformability of the polymers was evaluated in terms of the elastic modulus measured by DMA, and the crystallization time and thermal hysteresis of crystalline transition were measured by DSC.
Table I. Material properties measured by DSC

\begin{tabular}{cccccc}
\hline Sample & $\begin{array}{c}\text { PBS } \\
M_{\mathrm{n}}\end{array}$ & Linker & $\begin{array}{c}T_{\mathrm{c}}{ }^{*} \\
\left({ }^{\circ} \mathrm{C}\right)\end{array}$ & $\begin{array}{c}T_{\mathrm{m}}{ }^{*} \\
\left({ }^{\circ} \mathrm{C}\right)\end{array}$ & $\begin{array}{c}(1 / 2) \mathrm{tc} \\
(\mathrm{min})\end{array}$ \\
\hline 1 & 1,200 & LTI & - & 69 & 22.0 \\
\hline 2 & 1,900 & LTI & 20 & 83 & 6.0 \\
\hline 3 & 2,900 & LTI & 52 & 102 & -1.0 \\
\hline 5 & 1,900 & TIHI & 26 & 87 & 5.5 \\
\hline PBS & 1,900 & HMD & 57 & 111 & -1.5 \\
\hline
\end{tabular}

${ }^{*}$ Cooling and heating rates $=10^{\circ} \mathrm{C} / \mathrm{min}$. ${ }^{* *}$ Time delay of crystallization (peak top) at $20^{\circ} \mathrm{C}$ after rapid $\left(20^{\circ} \mathrm{C} / \mathrm{min}\right)$ cooling from $200^{\circ} \mathrm{C}$

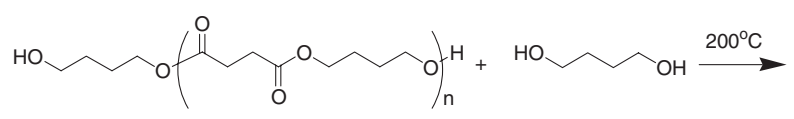
PBS, $M_{n}=40,000$

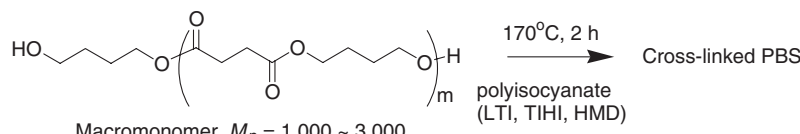
Macromonomer, $M_{\mathrm{n}}=1,000 \sim 3,000$

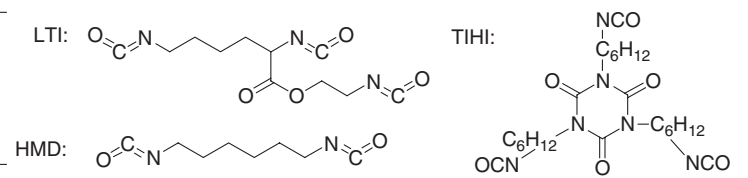

Scheme 1.

\section{RESULTS AND DISCUSSION}

Cross-linked PBSs (compounds 1, 2, 3, and 4) showed shape memory. The initial shape (a) was memorized stably by the network structure with covalent bonding, and the temporary shape (c) was fixed by the crystalline domain in the PBS macromonomer (Figure 1). Compounds 1, 2, and $\mathbf{4}$ were deformable at room temperature.

The melting points $\left(T_{\mathrm{m}}\right)$ and crystallization temperatures $\left(T_{\mathrm{c}}\right)$ of crosslinked compounds are listed in Table I, where a large difference between $T_{\mathrm{m}}$ and $T_{\mathrm{c}}$ is evident. The $T_{\mathrm{m}}$ and $T_{\mathrm{c}}$ values for compounds $\mathbf{1}, \mathbf{2}$, and $\mathbf{3}$ decrease with the density of cross-linking points (i.e., with the decrease of molecular weight of the macromonomers) because the stability of the 


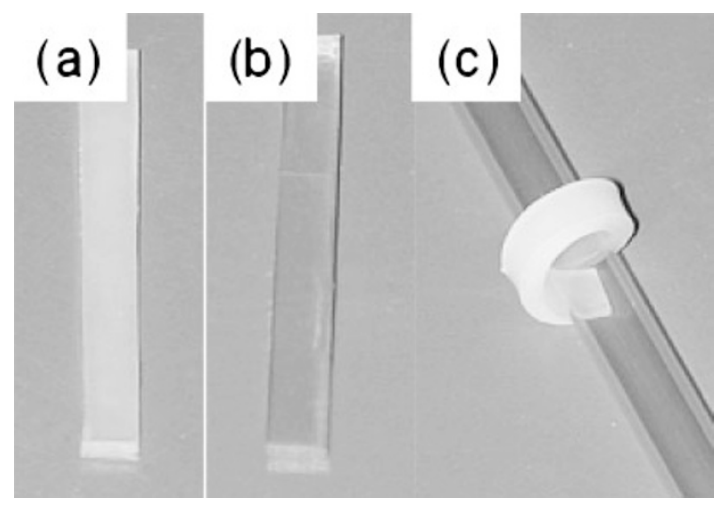

Figure 1. Shape memory of a cross-linked PBS. Compound 2 was heated to $100^{\circ} \mathrm{C}(\mathrm{a})$, rapidly cooled to room temperature (b), and then wound around a glass tube for $10 \mathrm{~min}$. The deformed shape (c) was recovered to the original shape (a) by heating.

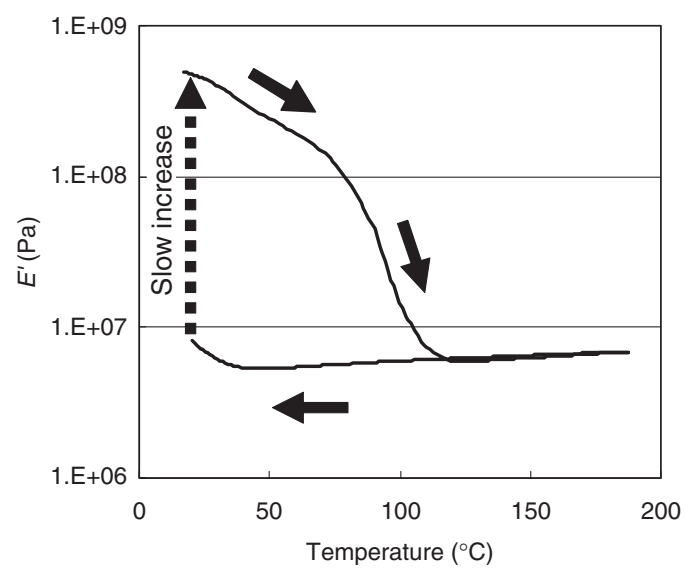

Figure 2. DMA thermogram of cross-linked PBS (compound 2). Heating and cooling rates $=10^{\circ} \mathrm{C} / \mathrm{min}$, oscillation $=10 \mathrm{~Hz}$, mode $=$ tension.

crystalline domain is due to the intermolecular force between the PBS macromonomer parts, but the difference between $T_{\mathrm{m}}$ and $T_{\mathrm{c}}$ is greater for compound $\mathbf{2}$ than for the less densely cross-linked compound $\mathbf{3}$. The stability of the temporary shape depends on $T_{\mathrm{m}}$, and the melting points of all the compounds are so much higher than room temperature that the temporary shapes were stable at room temperature. The temperature at which the material can be deformed to a temporary shape, on the other hand, is related to $T_{\mathrm{c}}$. Because compounds $\mathbf{2}$ and $\mathbf{4}$ have crystallization temperatures below body temperature, they can be deformed at temperatures below those causing burn injuries.

A large hysteresis in the elastic modulus of compound $\mathbf{2}$ is shown in Figure 2. A shape memory polymer is generally deformed in a lowelasticity region above the melting temperature of its crystalline domain and is fixed in a high-elasticity region below its crystallization temperature. These temperatures are usually close each other, so a heat-resistant shape memory polymer is not easy to deform at room temperature. The crystallization temperatures of compounds $\mathbf{2}$ and $\mathbf{4}$ are quite a bit lower than the corresponding melting temperatures and are near to room temperature. Deformation is therefore possible in a low-elasticity region around room temperature. It is well known that $T_{\mathrm{c}}$ is lowered by rapid cooling rate. These compounds, therefore, might be easier to deform at room temperature under a cooling condition faster than $10^{\circ} \mathrm{C} / \mathrm{min}$. The deformed shape becomes heat-resistant after slow increase of elastic

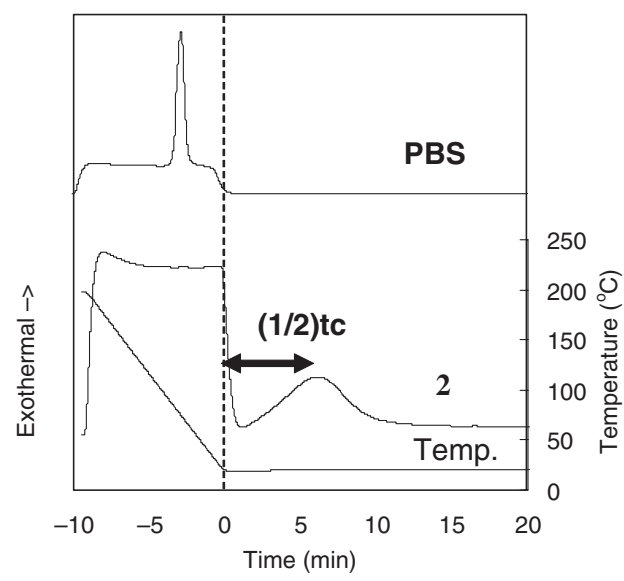

Figure 3. DSC thermograms of compound 2 and original PBS. Cooling rate $=20^{\circ} \mathrm{C} / \mathrm{min}$, constant temperature $=20^{\circ} \mathrm{C}$.

modulus at room temperature, which is caused by the increase of its crystallinity.

DSC measurement disclosed that the delay of crystallization time is caused by retardation of crystallization (Figure 3 ). The crystallization time increases with the increase of cross-linking density using small macromonomer. However, the delay of crystallization time was also observed when the linker was a diisocyanate (i.e., with compound 5). This means that the delay is caused not only by the 3D network effect, since the compound $\mathbf{5}$ is linear polymer. These compounds were cross-linked by urethane bonding, which is well known to form intermolecular hydrogen bonding each other. We guess that the hydrogen bonding disturbs the molecular motion and aggregation of PBS moiety to form crystalline domain and delay its crystallization time.

We conclude that the delay of crystallization time and the thermal hysteresis of crystalline phase transition caused by both the 3D network and the hydrogen bonding between urethane functions in the covalently bonded cross-linked structure enable the material to be easily deformed at room temperature because this network structure and this bonding restrain the PBS molecule and disturb the transition from the liquid phase to the crystal phase. Adjusting the density of the cross-linking points, therefore, controls the crystallization time of the cross-linked PBS. This shape memory polymer can be easily fitted to the human body without burning it and might therefore be used in products fitted directly to the body.

Received: April 20, 2009

Accepted: May 13, 2009

Published: June 24, 2009

\section{REFERENCES}

1. A. Lendlein and S. Kelch, Angew. Chem., Int. Ed., 41, 2034 (2002).

2. M. Irie, "Shape Memory Materials," K. Otuka and C. M. Wayman, Ed., Cambridge Univ. Press, Cambridge, UK, 1998, p 203.

3. A. Lendlein and R. Langer, Science, 296, 1673 (2002).

4. M. Ishii, Zairyo Gijutsu, 7, 183 (1989).

5. G. Zhu, G. Liang, Q. Xu, and Q. Yu, J. Appl. Polym. Sci., 90, 1589 (2003).

6. G. M. Zhu, Q. Y. Xu, G. Z. Liang, and H. F. Zhou, J. Appl. Polym. Sci., 95, 634 (2005).

7. F. Li, J. Hou, W. Zhu, M. Xu, X. Luo, D. Ma, and B. K. Kim, J. Appl. Polym. Sci., 62, 631 (1996).

8. C. Liu, S. B. Chun, P. T. Mather, L. Zheng, E. H. Haley, and E. B. Coughlin, Macromolecules, 35, 9868 (2002). 